\title{
Estimation and uncertainty analyses of grassland biomass in Northern China: Comparison of multiple remote sensing data sources and modeling approaches
}

\author{
Wenxiao Jia ${ }^{\mathrm{a}}$, Min Liu ${ }^{\mathrm{a}, *}$, Yuanhe Yang ${ }^{\mathrm{b}}$, Honglin $\mathrm{He}^{\mathrm{c}}$, Xudong Zhu ${ }^{\mathrm{d}, \mathrm{e}}$, Fang Yang ${ }^{\mathrm{a}}$, \\ Cai Yin ${ }^{\mathrm{f}}$, Weining Xiang ${ }^{\mathrm{a}}$ \\ a Shanghai Key Laboratory for Urban Ecological Processes and Eco-Restoration, School of Ecological and Environmental Sciences, East China Normal \\ University, Shanghai 200241, PR China \\ b State Key Laboratory of Vegetation and Environmental Change, Institute of Botany, Chinese Academy of Sciences, Beijing 100093, PR China \\ ${ }^{\mathrm{c}}$ Key Laboratory of Ecosystem Network Observation and Modeling, Institute of Geographic Sciences and Natural Resources Research, Chinese Academy of \\ Sciences, Beijing 100101, PR China \\ d Natural Resource Ecology Laboratory, Colorado State University, Fort Collins, CO 80523, USA \\ e Earth Sciences Division, Lawrence Berkeley National Laboratory, Berkeley, CA 94720, USA \\ ${ }^{f}$ School of Geography Sciences, East China Normal University, Shanghai 200241, PR China
}

\section{A R T I C L E I N F O}

\section{Article history:}

Received 3 February 2015

Received in revised form 27 August 2015

Accepted 1 September 2015

Available online 25 September 2015

\section{Keywords:}

Grassland biomass

NDVI

Root-to-shoot ratio

Uncertainty analysis

Northern China

\begin{abstract}
A B S T R A C T
Accurate estimation of grassland biomass and its dynamics are crucial not only for the biogeochemical dynamics of terrestrial ecosystems, but also for the sustainable use of grassland resources. However, estimations of grassland biomass on large spatial scale usually suffer from large variability and mostly lack quantitative uncertainty analyses. In this study, the spatial grassland biomass estimation and its uncertainty were assessed based on 265 field measurements and remote sensing data across Northern China during 2001-2005. Potential sources of uncertainty, including remote sensing data sources (DATsrc), model forms (MODfrm) and model parameters (biomass allocation, BMallo, e.g. root:shoot ratio), were determined and their relative contribution was quantified. The results showed that the annual grassland biomass in Northern China was $1268.37 \pm 180.84 \mathrm{Tg}$ (i.e., $532.02 \pm 99.71 \mathrm{~g} / \mathrm{m}^{2}$ ) during $2001-2005$, increasing from western to eastern area, with a mean relative uncertainty of $19.8 \%$. There were distinguishable differences among the uncertainty contributions of three sources (BMallo $>$ DATsrc $>$ MODfrm), which contributed $52 \%, 27 \%$ and $13 \%$, respectively. This study highlighted the need to concern the uncertainty in grassland biomass estimation, especially for the uncertainty related to BMallo.
\end{abstract}

(c) 2015 Elsevier Ltd. All rights reserved.

\section{Introduction}

Accounting for $40 \%$ of terrestrial earth surface, grassland plays an important role in global carbon cycle (World Resources Institute, 2000 , based on IGBP data). With a total area of 2.38 million square kilometers of grasslands in Northern China, it accounts for 9.92\% of the world's total grasslands (Fan et al., 2007; Scurlock and Hall, 1998). Accurate estimation of gross grassland biomass and its dynamics are crucial not only for the biogeochemical dynamics of terrestrial ecosystems, but also for the sustainable use of grassland resources (Luo et al., 2002).

There are various studies focused on grassland biomass estimation on regional to global scale with different data and methods

\footnotetext{
* Corresponding author. Tel.: +86 0215434 1140; fax: +86 02154341131.

E-mail address: mliu@re.ecnu.edu.cn (M. Liu).
}

(Fan et al., 2007; Hsu et al., 2012; Jiang et al., 2014; Luo et al., 2002; Ni, 2002; Ruppert et al., 2015; Scurlock et al., 2002). Compared with field measurement, which is the most basic, direct and authentic method, remote sensing provides an efficient and nondestructive way for grassland biomass estimation especially for regional scale research (i.e. options for spatial upscaling) (Fan et al., 2007). However, Scurlock and Hall (1998) and $\mathrm{Ni}(2002,2004)$ both concluded that a majority of previous studies probably gave inaccurate grassland biomass estimates because of limited data and approaches. Due to the large spatial heterogeneity and temporal dynamics of grassland across complex regions, the regional model simulations of grassland biomass inevitably suffered from deficiencies and uncertainties. Previous grassland biomass estimations were usually with large difference and short of quantitative uncertainty analysis (Fan et al., 2007; Fang et al., 2010; Ni, 2002; Piao et al., 2007). Hence, a more comprehensive grassland biomass assessment, including its magnitude and uncertainty is needed. Adequately addressing 
grassland biomass uncertainty in quantitative indicator evaluation remains a critical challenge (Keenan et al., 2011).

There remains no common agreement on best practices with respect to the characterization and propagation of uncertainties in regional model simulations of grassland biomass. Model simulations are usually associated with three uncertainty sources, namely, (1) observational uncertainties (incomplete and noisy observational data, systematic biases, etc.), (2) model structure uncertainties (e.g., the specification of model processes and internal relations), and (3) uncertainties in model parameters and states (Keenan et al., 2011). Specifically, the uncertainties in grassland biomass estimation via remote sensing mainly result from three sources: data sources (DATsrc), model forms (MODfrm), and model parameters (Piao et al., 2007; Scurlock et al., 2002). The first uncertainty source, i.e. DATsrc, originates from observational data (Ruppert and Linstädter, 2014), sensor differences, and the mismatch among various spatial resolution data (Fensholt and Proud, 2012; Tucker et al., 2005). Secondly, each model for grassland biomass estimation uses different equations to describe the correlations between vegetation indices and grassland biomass. The prevalent MODfrm includes linear, polynomial, power, logarithmic, and exponential function forms (Gao et al., 2013a; Jin et al., 2014; Yang et al., 2009). These regression models have performed well in Sahel of Africa (Tucker et al., 1985), Patagonia of Argentina (Gaitan et al., 2013), Colombia (Anaya et al., 2009), and China (Jin et al., 2014). Furthermore, a considerable amount of uncertainties remain in model parameters such as the ratios of root and shoot (R/S) (Wang et al., 2010; Yang et al., 2010). For example, a recent analysis indicated that $62 \%$ of $786 \mathrm{R} / \mathrm{S}$ estimates were unreliable (Mokany et al., 2006). However, previous grassland monitoring studies rarely quantified these uncertainties especially at regional scales. Therefore, it is urgent to determine how much confidence can be placed in previous study results (Ogle et al., 2010). Identifying the uncertainty sources and examining their propagation in regional grassland biomass estimations help us to better understand regional and global carbon cycling (Plischke et al., 2013).

The purpose of this paper is: (1) to provide grassland biomass estimation in Northern China during 2001-2005 based on the field measurements and remote sensing data; (2) to quantify the spatial uncertainty of regional grassland biomass, and (3) the relative contribution of each uncertainty source, addressing uncertainty in DATsrc, MODfrm and model parameters (BMallo, e.g. R/S). Our analysis aims to provide a quantitative perspective for uncertainty analysis of regional grassland biomass monitoring.

\section{Materials and methods}

\subsection{Study area}

The grassland area in Northern China covers $44.4 \%$ of the total administrative land area (Fig. 1). The mean annual temperature ranges from -3.1 to $8.9^{\circ} \mathrm{C}$. The mean annual precipitation shows a decreasing gradient from northeast $(694 \mathrm{~mm})$ to southwest $(62.7 \mathrm{~mm})$. Nine grassland types are distributed in the study area: alpine meadow (AM), alpine steppe (AS), alpine desert-steppe (AD), temperate meadow-steppe (TM), temperate steppe (TS), montane meadow (MM), warm-temperate tussock \& shrub-tussock (WT), tropical tussock \& shrub-tussock (TT), and temperate desert-steppe (TD). The distribution of grassland types was derived from the vegetation map of China at a scale of 1:1,000,000 (Chinese Academy of Sciences, 2001). Among the nine grassland types, AS, TS and TD account for $61.4 \%$ of total grassland area, whereas TT and WT only account for $0.6 \%$.
According to Köppen-Geiger climate classification (Kottek et al. 2006), $35 \%$ of the study region is covered by cold desert climate (BWk), followed by $31 \%$ tundra climate (ET), 13\% cold semi-arid climate (BSk), 9\% cool summer continental climate (Dwc), and 7\% warm summer continental climate (Dwb), respectively (Fig. 2). The remaining parts sum up 5\% with hot summer continental climates (Dwa), hot summer humid continental climate (Dfa), warm summer humid continental climate (Dfb), winter dry boreal climate (Dfc), hot summer subtropical climate (Cwa), and warm summer subtropical climate (Cwb).

\subsection{Data collection}

\subsubsection{Field data collection}

In this study, we selected data from 265 sites across Northern China (Fig. 1). Each site was visited once during the peak growing period within a time year frame (2001-2005; Yang et al., 2010). To measure above ground biomass (AGB), all plants in five plots $(1 \mathrm{~m} \times 1 \mathrm{~m}$, in the four corners and the center part of each site $(10 \mathrm{~m} \times 10 \mathrm{~m}))$ were harvested to ground level. The adherent soil, gravel, and litter were removed. To determine the below ground biomass (BGB), either three soil blocks $(0.5 \mathrm{~m} \times 0.5 \mathrm{~m} \times$ maximum soil depth) or nine soil cores with a diameter of $8 \mathrm{~cm}$ at depth intervals of $10 \mathrm{~cm}$ to maximum soil depth in 3 plots in any diagonal at each site were sampled. Roots of each sample were carefully separated from soil and other below ground material. Distinguished by color, fracture toughness and attached fine roots (Vogt and Persson, 1991), dead roots were removed. Roots were immediately placed in a cooler and then transported to the laboratory. Afterwards, they were washed free of residual soil under running deionized water $\left(<5^{\circ} \mathrm{C}\right)$. Finally, live shoots and roots were dried at $65^{\circ} \mathrm{C}$ to constant mass, and weighed to the nearest $0.1 \mathrm{~g}$. The detailed information for each sampling sites, including AGB, BGB, plant communities, location (longitude, latitude, and altitude), and its corresponding meteorological condition is described in Yang et al. (2010).

\subsubsection{Remote sensing data source}

Normalized difference vegetation index (NDVI) have been extensively applied in the regional or global grassland monitoring (Gao et al., 2013b; Muukkonen and Heiskanen, 2007; Xu et al. 2008). In this study, we downloaded NDVI during July to September in 2001-2005 from monthly MOD13A3 product of Moderate Resolution Imaging Spectroradiometer (MODIS) (NDVIMODIS), ten-day SPOT Vegetation (NDVI-SPOT), and biweekly dataset of Global Inventory Modeling and Mapping Studies (GIMMS; Tucker et al., 2004) of Advanced Very High Resolution Radiometer (AVHRR) (NDVI-AVHRR). The spatial resolutions of NDVI-MODIS, NDVI-SPOT, and NDVI-AVHRR datasets were 1, 1, and $8 \mathrm{~km}$, respectively. The annual $\mathrm{NDVI}_{\max }$ was calculated using the maximum value composite (MVC) of July to September to represent the annual maximum grassland greenness (Holben, 1986). Then annual NDVI $\max$ values were averaged to get a five-year mean $\mathrm{NDVI}_{\max }$. The $\mathrm{NDVI}_{\max }$ corresponding to locations of each site during 2001-2005 were obtained to establish grassland biomass models. Furthermore, the spatial distribution of $\mathrm{NDVI}_{\max }$ for the whole study area was also achieved. We also carried out the match assessment between the field observation and NDVI max. For every sampling site, we created buffers at a specific distance of $3 \mathrm{~km}$. Through zonal NDVI statistics within every buffer zone, we found that the standard deviations for the buffers were quite low with an average value of 0.04 , while a majority of the standard deviations were $<0.05$, which proved the high homogeneity of grassland and spatial representativeness between the correlated data. 


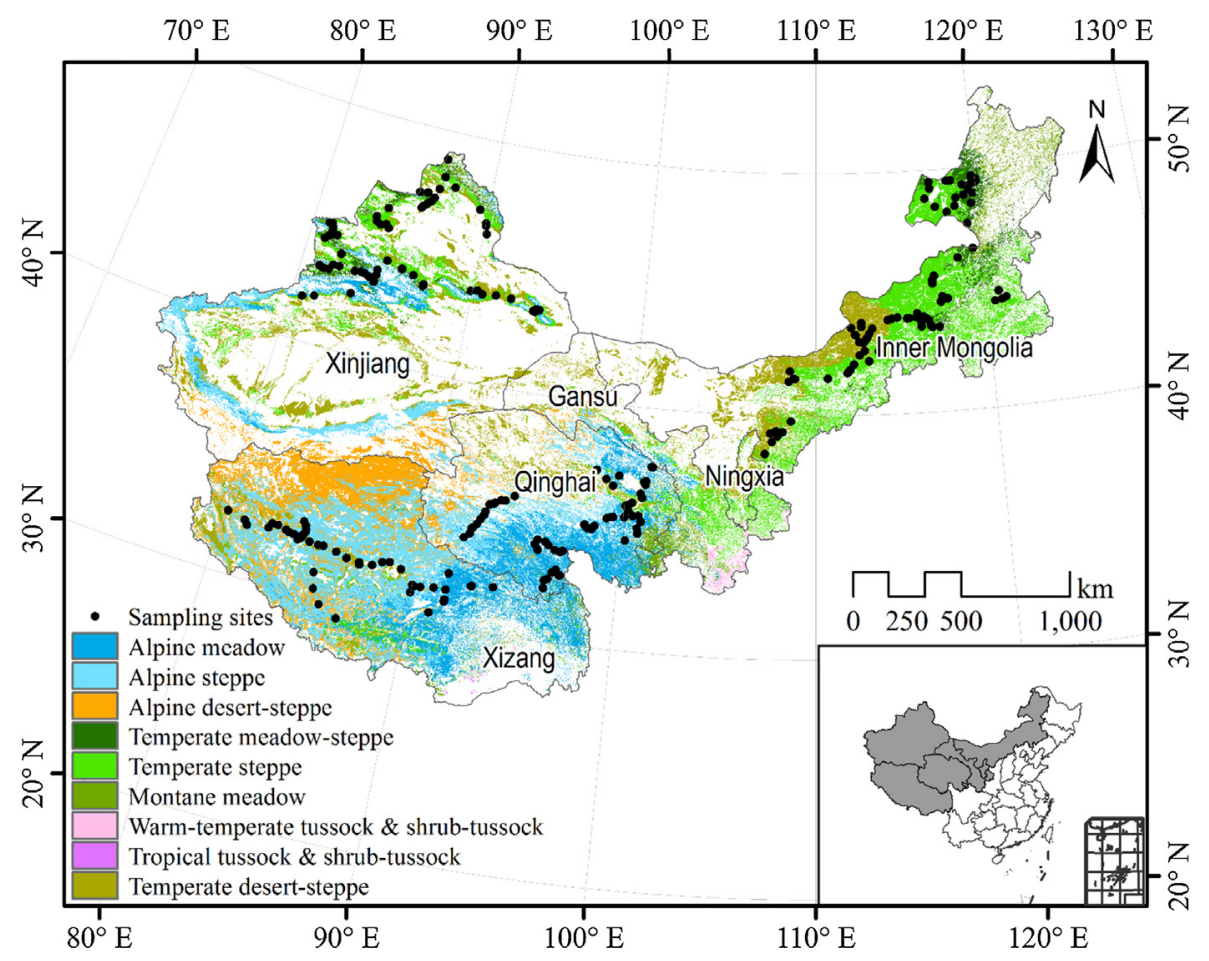

Fig. 1. Spatial distribution of 265 field sampling sites in the study area.

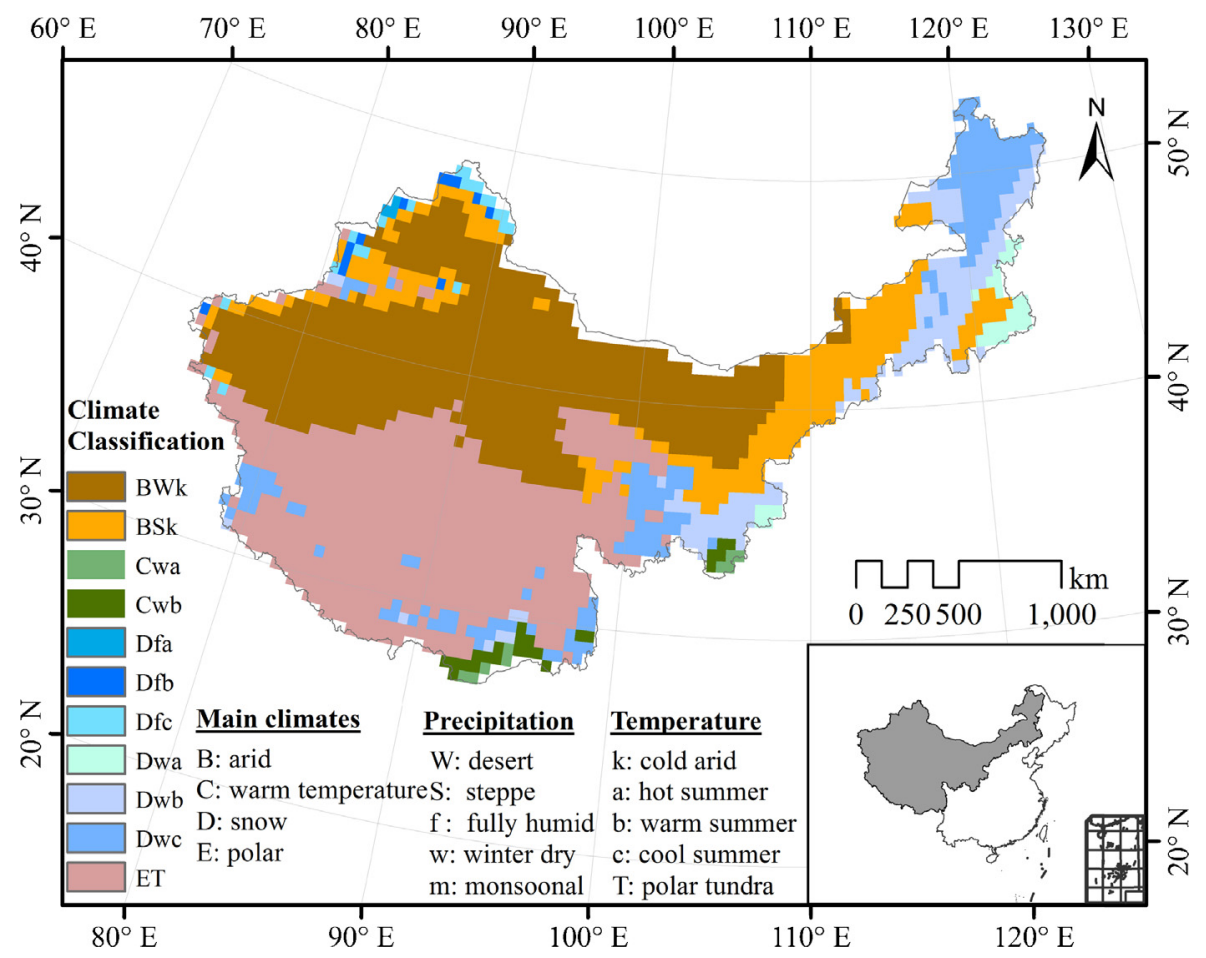

Fig. 2. The Köppen-Geiger climate classification in Northern China.

\subsection{Establishment and empirical validation of estimation models}

Grassland biomass included the simulation of AGB and BGB:

BMgrass $=f_{\mathrm{AGB}}\left(N D V I_{\max }\right)+f_{\mathrm{BGB}}(\mathrm{AGB}, \mathrm{R} / \mathrm{S})$

where BMgrass denotes the grassland biomass, $\left(\mathrm{g} / \mathrm{m}^{2}\right) . f_{\mathrm{AGB}}$ and $f_{\mathrm{BGB}}$ denote the functions used to estimate AGB and BGB, respectively. AGB estimation function used one of the three regression relationships between $\mathrm{NDVI}_{\max }$ and AGB field measurements, including linear (Yang et al., 2009), power (Jin et al., 2014) and exponential (Gao et al., 2013b) forms (see Eqs. (A1)-(A3) in Appendix A). And BGB was simulated based on the estimated AGB and vegetation-specific $R / S$.

In this study, eighty percent of the data were chosen randomly as the training set for model establishment, while the remaining data were the test set for model validation. The root mean squared 
Table 1

Biomass allocations with record R/S, sample R/S and allometric equation.

\begin{tabular}{|c|c|c|c|}
\hline Grassland type & Record R/S (Piao et al., 2007) & Sample R/S & Allometric equation (Yang et al., 2010) \\
\hline Alpine meadow (AM) & 7.91 & 7.36 & $\mathrm{BGB}=17.13 \times \mathrm{AGB}^{0.74}$ \\
\hline Alpine steppe (AS) & 4.25 & 5.68 & \\
\hline Alpine desert-steppe (AD) & 7.89 & 5.40 & \\
\hline Temperate meadow-steppe (TM) & 5.26 & 5.02 & \\
\hline Temperate steppe (TS) & 4.25 & 6.28 & \\
\hline Montane meadow (MM) & 6.23 & 5.14 & \\
\hline Warm-temperate tussock \& shrub-tussock (WT) & 4.42 & 4.42 & \\
\hline Tropical tussock \& shrub-tussock (TT) & 4.42 & 4.42 & \\
\hline Temperate desert-steppe (TD) & 7.89 & 7.58 & \\
\hline
\end{tabular}

Record R/S are root:shoot which were obtained from published records.

Sample R/S are the root:shoot based on the data for this study.

Table 2

Regression analysis between $\mathrm{NDVI}_{\max }$ and above-ground biomass (AGB) on site level in Northern China.

\begin{tabular}{|c|c|c|c|c|}
\hline Data source & $a$ & $b$ & $R^{2} /$ pseudo- $R^{2 \mathrm{a}}$ & $\Delta \mathrm{AIC}^{\mathrm{b}}$ \\
\hline \multicolumn{5}{|l|}{ Linear forms } \\
\hline $\mathrm{NDVI}_{\max }-\mathrm{MODIS}$ & 220.98 & 1.23 & 0.60 & 287.52 \\
\hline $\mathrm{NDVI}_{\max }-\mathrm{SPOT}$ & 231.07 & -3.16 & 0.59 & 410.34 \\
\hline $\mathrm{NDVI}_{\max }-\mathrm{AVHRR}$ & 228.32 & 4.95 & 0.54 & 528.51 \\
\hline \multicolumn{5}{|c|}{ Exponential forms } \\
\hline $\mathrm{NDVI}_{\max }-\mathrm{MODIS}$ & 21.45 & 2.91 & 0.61 & 0 \\
\hline $\mathrm{NDVI}_{\max }-\mathrm{SPOT}$ & 20.48 & 3.01 & 0.59 & 232.80 \\
\hline $\mathrm{NDVI}_{\max }-\mathrm{AVHRR}$ & 22.91 & 2.96 & 0.54 & 450.89 \\
\hline \multicolumn{5}{|l|}{ Power forms } \\
\hline $\mathrm{NDVI}_{\max }-\mathrm{MODIS}$ & 215.45 & 1.06 & 0.66 & 197.03 \\
\hline $\mathrm{NDVI}_{\max }-\mathrm{SPOT}$ & 219.72 & 1.10 & 0.62 & 323.67 \\
\hline $\mathrm{NDVI}_{\max }-\mathrm{AVHRR}$ & 232.87 & 1.07 & 0.59 & 479.66 \\
\hline
\end{tabular}

${ }^{a} R^{2}$ of the non-linear regressions stands for pseudo- $R^{2}$.

b $\triangle$ AIC: model's AIC minus minimal AIC.

error (RMSE, see Eq. (A6) in Appendix A) and the correlation coefficient $(R)$ were used to evaluate the performance of the models. We also examined the relative model parsimony through Akaike Information Criterion (AIC; see Eq. (A7) in Appendix A; Burnham and Anderson, 2002). AIC deals with the trade-off between the goodness of fit of the model and the complexity of the model. According to Akaike's theory, the preferred model is the one with the minimum AIC value.

\subsection{Uncertainty analysis of grassland biomass estimation}

\subsubsection{Determination of uncertainty in DATsrc, MODfrm and BMallo}

This study addressed three uncertainty sources including DATsrc, MODfrm, and BMallo in grassland biomass estimation. Three widely accessible and commonly used NDVI datasets, i.e., NDVIMODIS, NDVI-SPOT, and NDVI-AVHRR, were considered to figure out the influence of DATsrc on regional grassland biomass estimation. As to model structure, we tested linear, exponential, power, logarithmic and polynomial forms and finally chose linear, power and exponential cases as representative function forms. Further, to examine the uncertainty contribution of model parameters, BGB models were established using three BMallo schemes, which recorded $\mathrm{R} / \mathrm{S}$, sample $\mathrm{R} / \mathrm{S}$ and allometric equation (Table 1 ). The record $\mathrm{R} / \mathrm{S}$ were collected from massive references about Chinese terrestrial ecosystems (Piao et al., 2007). Sample R/S were based on our large-scale biomass survey. The allometric equation was obtained on the same field survey data (Yang et al., 2010). Yang et al. (2010) explored relationships between AGB and BGB and suggested that $A G B$ was nearly proportional to BGB with a consistent scaling exponent (the slope of log-log linear relationship between AGB and BGB) of 1.02 across various grassland types (Yang et al., 2010).

\subsubsection{Estimation of regional grassland biomass and its} uncertainty

With three uncertainty sources, 27 distinct grassland biomass estimation models (3 DATsrc*3 MODfrm*3 BMallo) were obtained, and the average grassland biomass for each pixel as the final estimation across the region was calculated:

BMgrass $_{h}=\frac{1}{27} \sum_{i=1}^{27}$ BMgrass $_{h i}$

where $h$ stands for the $h$ th pixel of study region, $i$ stands for the $i$ th estimation result using different approaches.

The relative uncertainty of grassland biomass for each pixel across the study region was expressed as the standard deviation divided by the mean prediction value:

Uncertainty $_{h}(\%)=\sqrt{\frac{1}{27} \sum_{i=1}^{27} \frac{\left(\text { BMgrass }_{h i}-\text { BMgrass }_{h}\right)^{2}}{\text { BMgrass }_{h}}} \times 100$

\subsubsection{Uncertainty partitioning using factorial analysis}

In addition to quantify the uncertainty in grassland biomass estimation, it is also important to understand the relative contribution of each source of uncertainty to total uncertainty and locate the most influential model input. In this study, effect-size metrics $\left(\eta^{2}\right.$ $\omega^{2}$ ) based on analysis of variance (ANOVA) sums of squares were used to decompose grassland biomass uncertainty into different model factors (i.e. DATsrc*MODfrm*BMallo) and their interactions. By calculating and comparing $\eta^{2}$ and $\omega^{2}$, model factor which had small or large impact on the variance of grassland biomass estimation, could be determined. Thus, we could concentrate on the most influential uncertainty source of grassland biomass estimation. In addition, this analysis provided information about the relative role of the different factors in the total uncertainty; however, it was not directly related to the magnitude of the uncertainty. 


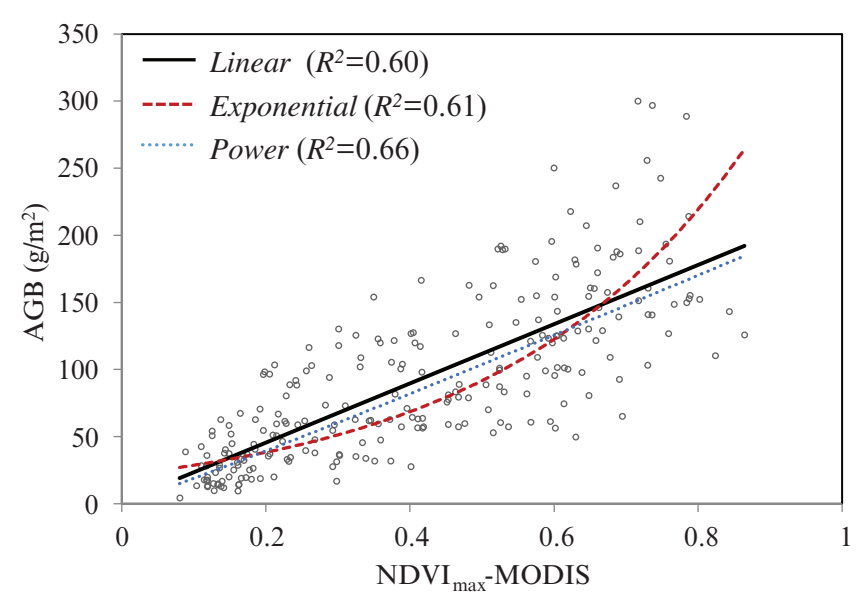

Fig. 3. Relationship of above-ground biomass (AGB) and NDVI $\mathrm{max}_{\mathrm{m}}-\mathrm{MODIS}$ on site level in Northern China grassland during 2001-2005.

\section{Results}

\subsection{Grassland biomass modeling and validation on site level}

The statistical analysis for AGB versus NDVI indicated that $\mathrm{NDVI}_{\max }$ from all three datasets exhibited significant correlations with AGB $(P<0.001)$ across these three model forms, with the coefficient of determination $\left(R^{2}\right)$ for linear regressions and pseudo- $R^{2}$ for non-linear regressions ranging between 0.54 and 0.66 (Table 2 , Fig. 3; Figs. B2 and B3 in Appendix B). With regard to goodness of fit, the model between AGB and $\mathrm{NDVI}_{\text {max }}$-MODIS employing the exponential form performed best with minimum AIC.

We also compared the total grassland biomass estimation from 27 formulations. The results were illustrated in a Taylor diagram (Fig. 4), in which four statistical quantities were geometrically connected: $R$, RMSE, standard difference of observation and standard difference of predicted value (Taylor, 2001). The polar axes displayed the correlation coefficient and the radial axes indicated the RMSE of the model variable. Simulated patterns matched well with observations lie nearest the observed point on the $x$ axis, with relatively high correlation and low RMSE. By integrating the consideration of $R$ and RMSE, as shown in Fig. 4, we noted that: (1) record $R / S$ from references fitted worse than field sample $R / S$ and Yang's allometric equation (the points marked with " $R$ " was the farthest to the observed point), (2) NDVI-MODIS provided a slightly better agreement with field measurements than NDVI-SPOT and NDVI-AVHRR datasets (the points marked with "M" were the nearest to the observed point than the points marked with " $\mathrm{S}$ " and "A"), and (3) no significant difference existed across three function forms (the distances of the points marked with "e", "l", and "p" from the observed point were almost equal). Furthermore, we used AIC to measure the model quality in the relative sense (see Table C2 in Appendix C). Among these 27 combinations, the preferred model is the one using NDVI-MODIS, exponential function and field sample $\mathrm{R} / \mathrm{S}$ with the relative minimum AIC value.

\subsection{Spatial distribution of grassland biomass estimation and uncertainty}

The grassland biomass in Northern China was calculated using 27 formulations of biomass empirical models (with different DATsrc, MODfrm, and BMallo) during 2001-2005. The result showed that substantial spatial heterogeneity existed in grassland biomass estimation of Northern China (Fig. 5a), with an average biomass density of $532.02 \pm 99.71 \mathrm{~g} / \mathrm{m}^{2}$ (i.e., $1268.37 \pm 180.8 \mathrm{Tg}$ ). The regional biomass density decreased from northeast to southwest.
Different grassland types held different productivity (Table 3). AS and $\mathrm{AD}$ in the northwest possessed lower productivity than TM, TS in the medium part. And MM, WT, TT in the east held the highest productivity. The difference for each climate classification was also analyzed. The biomass density for BWk was the lowest with $291.30 \mathrm{~g} / \mathrm{m}^{2}$, while Dwc was the largest with $924.23 \mathrm{~g} / \mathrm{m}^{2}$.

The uncertainty of biomass was derived with the 27 distinct estimation models (Fig. 5b). The relative uncertainty across the region averaged about $19.8 \%$, decreasing from $30 \%$ in the west to $2.6 \%$ in the east, with the largest uncertainty occurring in regions with lower biomass. The relative uncertainty varied with different grassland types and climate classifications. For example, alpine grasslands (i.e. AM, AS, AD) held larger uncertainty (20-40\%), while temperate and tropical grasslands (i.e. TD, TS, TT, WT) held uncertainty below $20 \%$. The area with climate of BWk showed the largest uncertainty ( $>30 \%$ ), while area with continental climate demonstrated lower relative uncertainty $(<20 \%)$.

\subsection{Uncertainty partitioning of the modeled grassland biomass}

With effect-size metrics, the importance of uncertainty sources to the grassland biomass estimation was measured (Table 4, Fig. 6). Most uncertainty was contributed by BMallo (52\%) and DATsrc (27\%), while MODfrm only contributed $13 \%$. The second order effects (interactions) were low so that the three factors seemed to be independent from each other.

In addition, the portions for three uncertainty sources largely varied across grassland types or climate classifications. BMallo generated the largest portion of uncertainty for most grassland types (80\% for TM and $77 \%$ for TS), where DATsrc and MODfrm contributed the lowest uncertainty. For WT and TT, BMallo only contributed less than $2 \%$ uncertainty largely due to the same value of $\mathrm{R} / \mathrm{S}$ entries, while DATsrc contributed the largest uncertainty (69\% for WT and 45\% TT). MODfrm generated largest uncertainty for $\mathrm{AD}$ (with 58\%) and TD (with 40\%). As to climate classifications, BMallo was the largest uncertainty contributor for Dwa (with 84\%) and Dwb (with 79\%), while DATsrc contributed the largest contribution for Dfc, Dfa, Dfb, Cwa and Cwb with about 50-68\%. MODfrm generated the largest uncertainty for BSk with $50 \%$.

\section{Discussion}

\subsection{Statistical models for grassland biomass estimation}

In this study, considering different remote sensing DATsrc, MODfrm, and BMallo, 27 distinct models were established for the grassland biomass estimation in Northern China. For DATsrc, NDVIMODIS appeared to be superior to NDVI-SPOT and NDVI-AVHRR Northern China. This could be associated with the higher spatial and spectral resolution of MODIS (Tarnavsky et al., 2008). The red channel and NIR channel of MODIS are narrower than that of SPOTVGT and AVHRR, which lead to the NDVI products' superiority of chlorophyll sensitiveness (Fensholt and Proud, 2012). In addition, we obtained the correlations among five-year mean $\mathrm{NDVI}_{\max }$ to examine the harmonization of AVHRR, SPOT-VGT, and MODIS. It showed that NDVI $\max$ between SPOT and MODIS were more consistent with $R=0.97$, while NDVI-AVHRR with NDVI-MODIS matched worst with $R=0.88$ (see Fig. B1 in Appendix B). The spatial variability for NDVI-MODIS and NDVI-SPOT were proved to be higher than NDVI-AVHRR (Tarnavsky et al., 2008).

Interestingly, the model performances of vegetation-specific R/S and the allometric equation were about the same (Fig. 4). The allometric approach suggested that AGB scales isometrically with BGB across diverse grassland types, which implied allometric theory might substitute at least a part of the labor-intense work for 


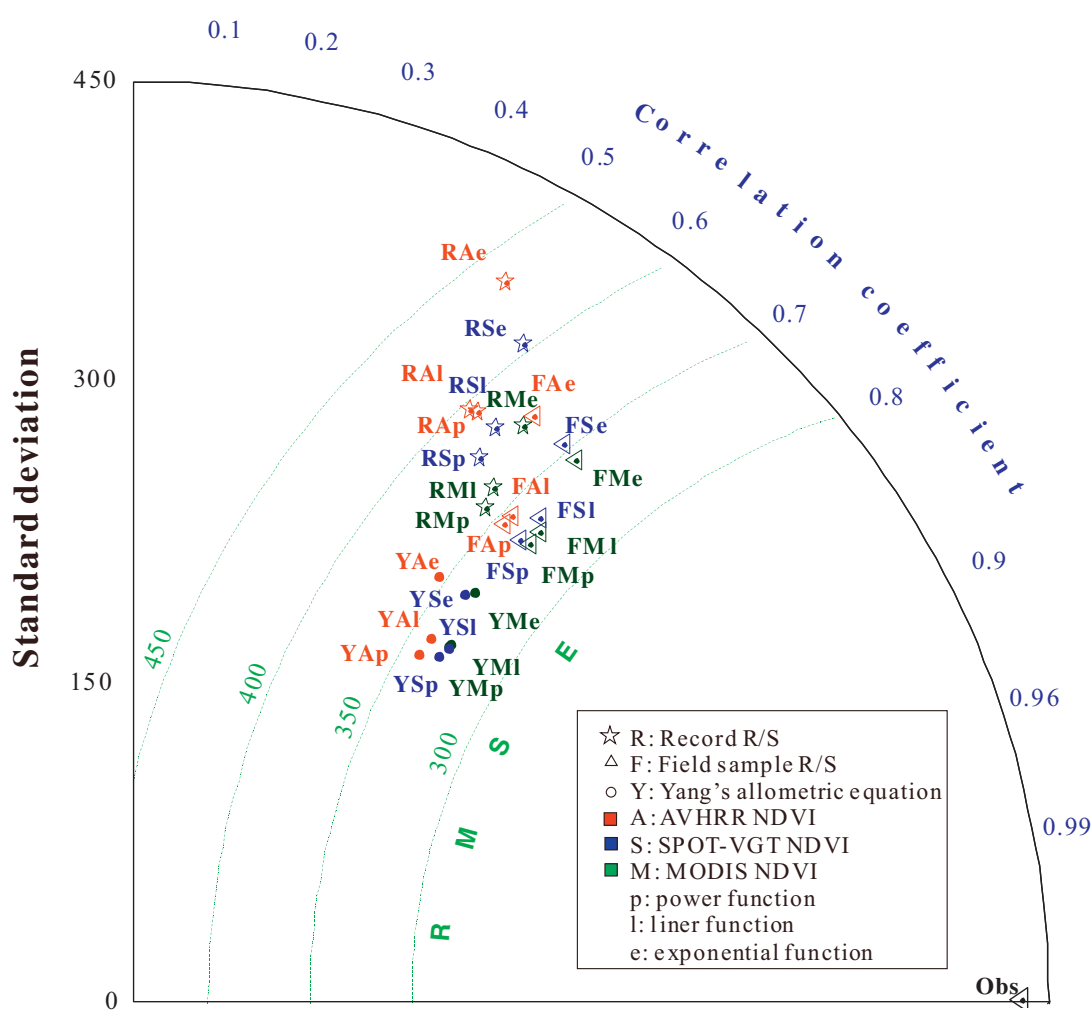

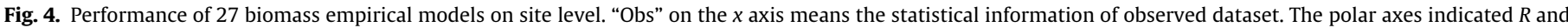
the radial axes indicated RMSE. The best fit models lied nearest the observed point on the $x$ axis, with relatively high $R$ and low RMSE.

R/S. This might chime with some plant physiological evidences that although different photosynthesis pathways could occur in different plant species, the basic photosynthetic characteristics were still the same (Oliveras et al., 2014). This result was supported by the isometric theory (Enquist and Niklas, 2002; Niklas, 2005). The information could increase the feasibility of quantifying and monitoring grassland biomass change over time and land use change.

\subsection{Grassland biomass estimation in Northern China}

In this study, we calculated the total grassland biomass for Northern China and obtained an estimate of $532.02 \pm 99.71 \mathrm{~g} / \mathrm{m}^{2}$ (1268.37 $\pm 180.84 \mathrm{Tg}, 5$ year-averaged). This result was in the range of previously reported results $\left(479.56-2551.56 \mathrm{~g} / \mathrm{m}^{2}\right.$, Fan et al., 2007; Fang et al., 2010; Ni, 2002; Piao et al., 2007). We noticed that the previous estimations were subject to large differences. The maximum grassland biomass density was almost 6 times of the minimum value. The grassland biomass estimation in our study was close to satellite-based estimation of $543.56 \mathrm{~g} / \mathrm{m}^{2}(1238.89 \mathrm{Tg})$ (Ma et al., 2010); however, much lower than the global mean grassland biomass density values which were used by Ni (2002). Besides modeling approaches, the discrepancy among different studies might originate from variations of field locations, sampling periods and/or estimation algorithms (Ma et al., 2010; Piao et al., 2007; Ruppert and Linstädter, 2014).

The estimation in this study was in agreement with Ma et al. (2010) with the same period data. Furthermore, the peak biomass method was more suitable for temperate grassland with short growing season (Scurlock et al., 2002). Thus, our study may underestimate biomass in tropical grasslands. In the end, the R/S also led to large disparities in grassland biomass estimation. Wang et al. (2010) pointed that BGB in grassland tended to be overestimated due to the high $R / S$ in previous reports. The mean value of $R / S$ used by Fan et al. (2007) was 24.6 (2.4-52.3), which was three times higher than the record R/S of 7.7(5.3-10.1) (Piao et al., 2007), four times higher than the sample R/S of 5.7 (0.4-14.3) (Yang et al., 2010).

\subsection{Spatial distribution of grassland biomass and relative uncertainty}

The decrease in grassland biomass from the east to the west is likely driven by climatic factors. Located in the headstream of the Yangtze River, the Yellow River and the Mekong River, the grassland biomass in the south of Qinghai exhibited higher patterns with higher solar radiation. Overall, the higher temperature, higher precipitation and lower elevation could result in the higher grassland biomass density in the southeast. Previous researches also suggested that carbon storage tended to accumulate in area where climatic factors were suitable (Gao et al., 2013a; Jiang et al., 2014; Kang et al., 2013; Mao et al., 2014; Wang et al., 2014; Xia et al., 2014). Moreover, anthropogenic factor (e.g., forage, fire, green project etc.) might explain variability in grassland biomass production (Kawamura et al., 2005; Mokany et al., 2006; Blanco et al., 2014; Carilla et al., 2011; Valone and Kelt, 1999). Chen et al. (2014) referred that human activities on Chinese alpine grassland significantly intensified in 2001-2005.

The uncertainty of estimated biomass in Northern China grasslands was $19.8 \%$, decreasing from the west to the east, with the largest uncertainty occurring in area with lower biomass. The variation patterns of uncertainty were most likely due to the aridity gradients (Fan et al., 2007). R/S decreased with increasing aridity, causing the particularly larger uncertainty for alpine grasslands with high aridity, and the lower uncertainty for tropical grasslands with low aridity. Another reason for higher uncertainty is the lower productivity of these systems and a relatively increased measurement error with field measurements. While the absolute 

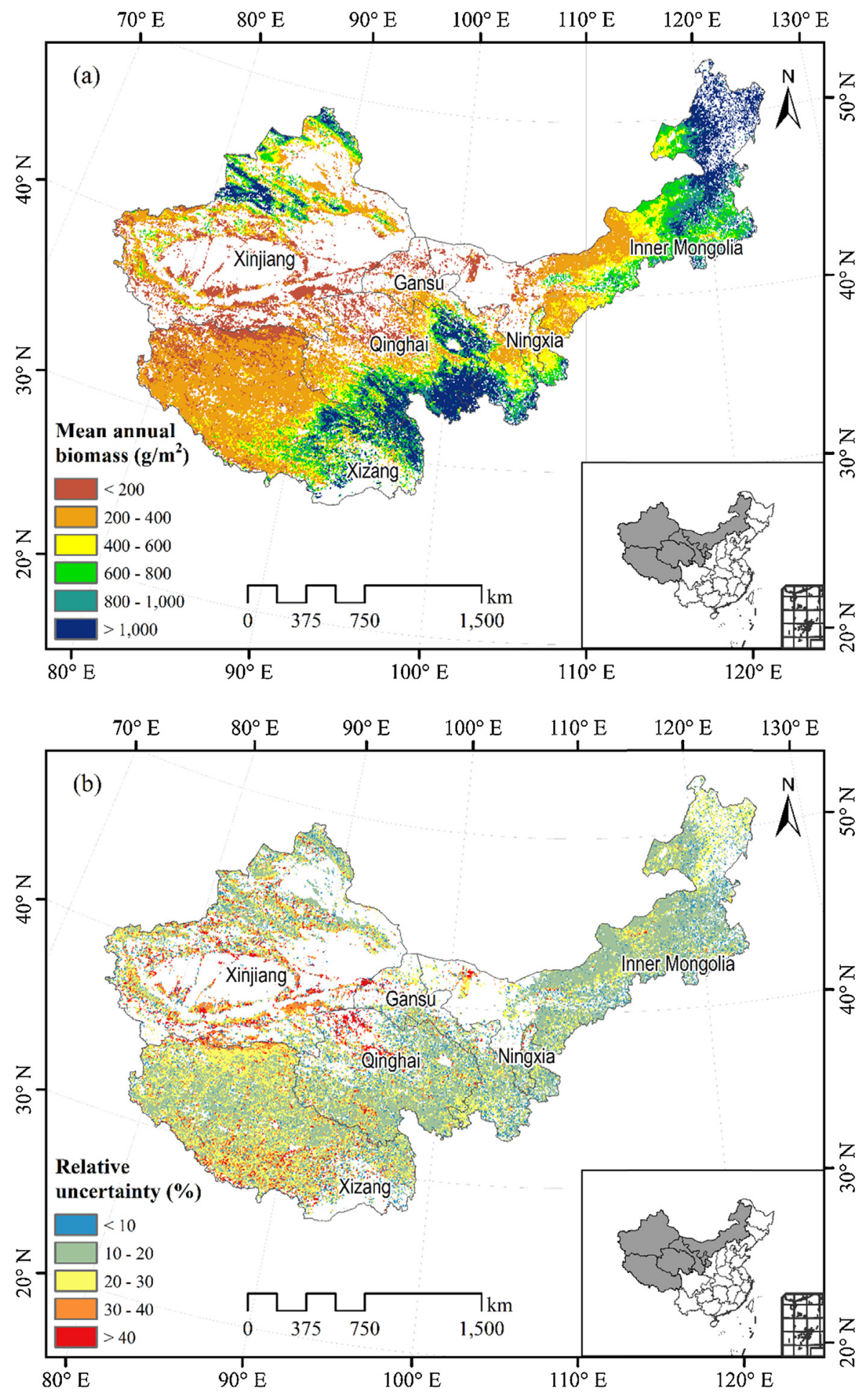

Fig. 5. Spatial patterns of (a) mean annual biomass and (b) the relative uncertainty (RU) of pixel level in Northern China grassland during $2001-2005$.

measurement error (e.g. due to the residual biomass left on the plot) is rather constant with field measurements, the relative measurement error of course increases with decreasing standing biomass. Moreover, the deficiency of sampling sites and absence of hyperspatial data would lead to large biomass estimation uncertainty. Rahman et al. (2003) pointed out that the optimal pixel size for studying functional properties of grasslands was $6 \mathrm{~m}$ or less, which was much smaller than the pixel size in this study. It was worth noting that the sampling sites selected in our study ensured large distance between distinct blocks and grasslands in Northern China were widely and continuously distributed, which could increase the spatial representativeness of sampling sites to some extent. Overall, to improve the model accuracy, it was urgent to increase the spatial representativeness of field measurements based on more continuous grassland samples and higher spatial-temporal resolution remote sensing data. Compared with previous studies, the uncertainty obtained in the present study was lower than Piao et al. (2007), which suggested a $35.9 \%$ overall uncertainty of grassland biomass estimates based on NDVI-AVHRR and the grassland resource inventory method. This superiority gave credit for the 
Table 3

Grassland biomass in Northern China during 2001-2005.

\begin{tabular}{|c|c|c|c|c|c|c|}
\hline & \multirow[t]{2}{*}{ Class } & \multirow[t]{2}{*}{ Area $\left(10^{4} \mathrm{~km}^{2}\right)$} & \multicolumn{2}{|l|}{$\begin{array}{l}\text { Grassland } \\
\text { biomass } \\
\text { density }\left(\mathrm{g} / \mathrm{m}^{2}\right)\end{array}$} & \multicolumn{2}{|l|}{$\begin{array}{l}\text { Grassland } \\
\text { biomass (Tg) }\end{array}$} \\
\hline & & & Range & Mean & Range & Mean \\
\hline \multirow[t]{9}{*}{ Grassland type } & Alpine meadow (AM) & 38.41 & $704.42-1062.29$ & 883.36 & $270.58-408.07$ & 339.33 \\
\hline & Alpine steppe (AS) & 58.93 & $301.31-468.56$ & 384.93 & $177.56-276.11$ & 226.84 \\
\hline & Alpine desert-steppe (AD) & 32.94 & $195.18-316.24$ & 255.71 & 64.29-104.16 & 84.22 \\
\hline & $\begin{array}{l}\text { Temperate meadow-steppe } \\
\text { (TM) }\end{array}$ & 8.97 & 910.98-1216.49 & 1063.73 & 81.76-109.16 & 95.44 \\
\hline & Temperate steppe (TS) & 48.89 & $481.73-708.16$ & 594.96 & $235.53-346.24$ & 290.89 \\
\hline & Montane meadow (MM) & 10.87 & 831.09-1244.16 & 1037.62 & $90.36-135.27$ & 112.80 \\
\hline & $\begin{array}{l}\text { Warm-temperate tussock \& } \\
\text { shrub-tussock (WT) }\end{array}$ & 1.12 & 836.07-1124.91 & 980.49 & $9.38-12.6$ & 10.98 \\
\hline & $\begin{array}{l}\text { Tropical tussock \& } \\
\text { shrub-tussock (TT) }\end{array}$ & 0.07 & $891.76-1265.13$ & 1078.44 & $0.64-0.93$ & 0.80 \\
\hline & Temperate desert-steppe (TD) & 38.19 & $160.32-385.54$ & 271.43 & $59.38-142.78$ & 107.07 \\
\hline \multirow[t]{11}{*}{ Climate classification } & Cold desert climate (BWk) & 46.31 & $191.15-391.44$ & 291.30 & 88.53-181.29 & 134.91 \\
\hline & Cold semi-arid climate (BSk) & 40.41 & $399.28-643.82$ & 521.55 & $161.35-260.17$ & 210.76 \\
\hline & $\begin{array}{l}\text { Hot summer subtropical } \\
\text { climate (Cwa) }\end{array}$ & 0.55 & $845.06-998.10$ & 921.58 & $4.68-5.53$ & 5.10 \\
\hline & $\begin{array}{l}\text { Warm summer continental } \\
\text { climate }(\mathrm{Cwb})\end{array}$ & 1.66 & $829.76-1015.73$ & 922.74 & $13.78-16.87$ & 15.32 \\
\hline & $\begin{array}{l}\text { Hot summer humid } \\
\text { continental climate (Dfa) }\end{array}$ & 0.55 & $531.51-606.36$ & 568.94 & $2.94-3.36$ & 3.15 \\
\hline & $\begin{array}{l}\text { Warm summer humid } \\
\text { continental climate (Dfb) }\end{array}$ & 1.85 & $478.48-809.80$ & 644.14 & $8.83-14.94$ & 11.89 \\
\hline & Winter dry boreal climate (Dfc) & 3.32 & $537.70-881.60$ & 709.65 & $17.86-29.28$ & 23.57 \\
\hline & $\begin{array}{l}\text { Hot summer continental } \\
\text { climates (Dwa) }\end{array}$ & 3.51 & $711.13-830.75$ & 770.94 & 24.93-29.12 & 27.03 \\
\hline & $\begin{array}{l}\text { Warm summer continental } \\
\text { climate (Dwb) }\end{array}$ & 21.22 & 756.24-979.40 & 867.82 & $160.47-207.83$ & 184.15 \\
\hline & $\begin{array}{l}\text { Cool summer continental } \\
\text { climate (Dwc) }\end{array}$ & 23.25 & $732.52-1115.94$ & 924.23 & $170.32-259.45$ & 214.88 \\
\hline & Tundra climate (ET) & 95.77 & $300.23-620.18$ & 460.20 & $285.49-589.73$ & 437.61 \\
\hline Total & Northern China & 238.40 & $432.31-631.73$ & 532.02 & 1087.53-1449.21 & 1268.37 \\
\hline
\end{tabular}

Table 4

The ANOVA table with uncertainty sources of grassland biomass in Northern China.

\begin{tabular}{|c|c|c|c|c|c|c|c|}
\hline Source & SS & df & Mean square & $F$ & $p$ & $\eta^{2}$ & $\omega^{2}$ \\
\hline DATsrc & 2458.748 & 2 & 1229.374 & 507.068 & 0.000 & 0.27 & 0.27 \\
\hline MODfrm & 1132.883 & 2 & 566.441 & 233.635 & 0.000 & 0.13 & 0.13 \\
\hline BMallo & 4654.337 & 2 & 2327.168 & 959.864 & 0.000 & 0.52 & 0.52 \\
\hline DATsrc*MODfrm & 559.104 & 4 & 139.776 & 57.652 & 0.000 & 0.06 & 0.06 \\
\hline DATsrc*BMallo & 90.596 & 4 & 22.649 & 9.342 & 0.004 & 0.01 & 0.01 \\
\hline MODfrm*BMallo & 40.058 & 4 & 10.015 & 4.131 & 0.042 & 0.00 & 0.00 \\
\hline Error & 19.396 & 8 & 2.424 & & & & \\
\hline Total & 8955.123 & 26 & & & & & \\
\hline
\end{tabular}

approach based on multiple remote sensing vegetation indices and field measurements (Piao et al., 2007).

\subsection{Uncertainty partitioning in grassland biomass estimations}

The uncertainty in grassland biomass simulation results from a combination of conceptual and functional model attributes such as model structure, data inputs, and model parameters (Verstraeten et al., 2008). Uncertainty partitioning analysis could sharpen our view on the key drivers and propagation of uncertainty (Plischke et al., 2013). In this study, BMallo is the primary uncertainty source of grassland biomass estimation, contributing $52 \%$. This could be confirmed with the facts that BGB accounted for almost $88 \%$ of grassland biomass in China, yet the difficulties in observing and measuring root biomass still existed (Fan et al., 2007). Intensive and systematic studies upon BMallo are still lacking. In addition, DATsrc contributed considerable uncertainty with $27 \%$ contribution, and MODfrm contributed 13\% uncertainty in grassland biomass estimation. The amount of variability of the three NDVI dataset used in the calculation was more important than the specific mathematical operations, which was also illustrated in Lauenroth et al. (2006). If the model is very sensitive to an input with very small uncertainty, then the uncertainty contribution of this input might be small, and vice versa (He et al., 2014). For example, the larger uncertainty in regions with lower biomass could be attributed to the greater variability among three NDVI datasets. Model structure was a very important uncertainty source in grassland biomass estimation. The lowest uncertainty contribution from MODfrm could partly related to the relatively low model performances $(0.60-0.66$, Fig. 3). Notably, the interaction between DATsrc and MODfrm also contributed $6 \%$ of uncertainty. The extrapolation from a plot on the ground to satellite data of a pixel size explained the interaction of uncertainty sources (Gao et al., 2013b).

This research evaluated only three uncertainty sources associated with the grassland biomass estimation in Northern China. The estimation models used in the present study were only based on the remote sensing approach, not covering all models especially for the physiological model, although the latter might be more accurate. 

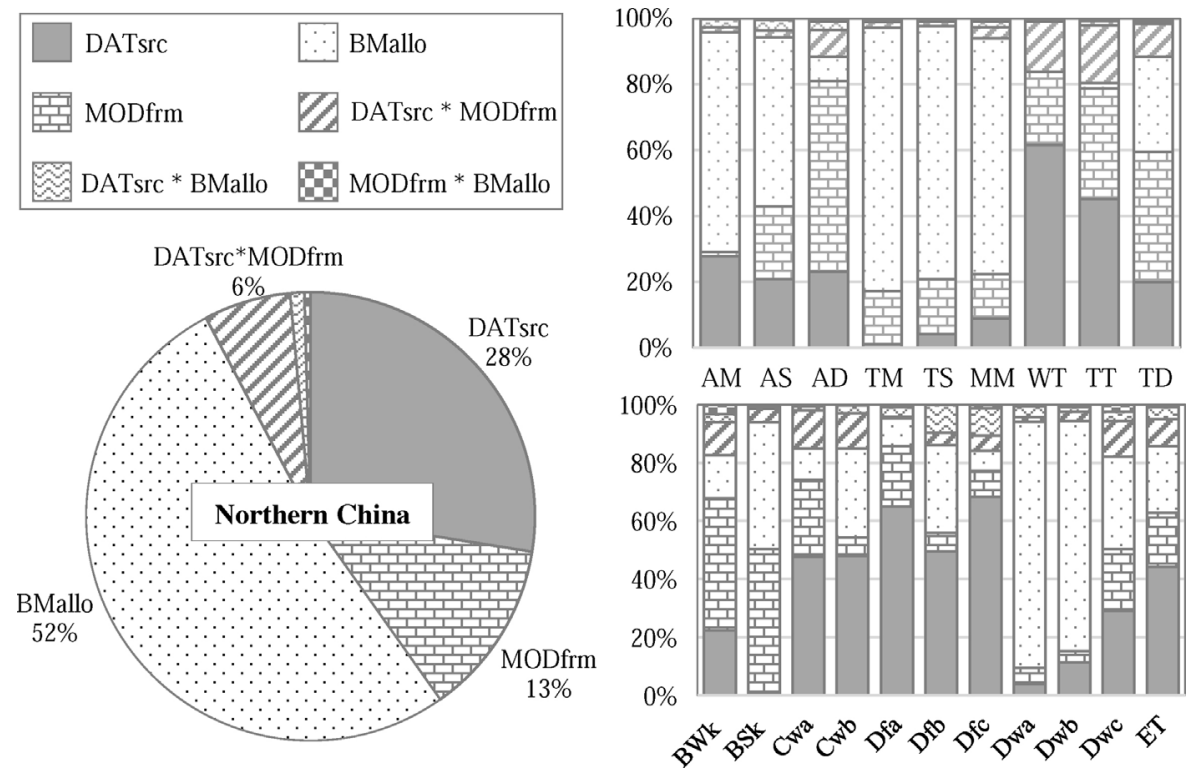

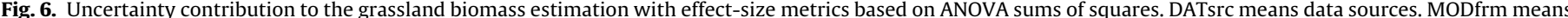

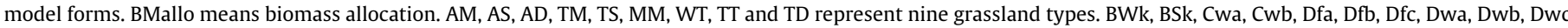
and ET represent eleven climate classifications. Note: The contribution weights $<1 \%$ were not illustrated.

The influence of these models on the biomass estimation uncertainty still need further study. Furthermore, grassland biomass was also significantly affected by many other factors such as different vegetation indices, sampling error, research-scale etc. For the analyses of these uncertainty sources, we need to conduct further and deeper research to sharpen our view for grassland biomass estimation.

\section{Conclusions}

We evaluated the magnitude and spatial pattern of grassland biomass in Northern China by integrating field sampling measurements and multiple-source satellite data. The uncertainty of grassland biomass estimation was also quantified with respect to the uncertainty contribution from three remote sensing DATsrc, three MODfrm and three model parameters (i.e. BMallo). The annual grassland biomass in Northern China during 2001-2005 was $1268.37 \pm 180.84 \mathrm{Tg}\left(532.02 \pm 99.71 \mathrm{~g} / \mathrm{m}^{2}\right)$. Spatially, grassland biomass in Northern China exhibited a large spatial variability, increasing from the west to the east. The mean relative uncertainty of grassland biomass in Northern China was estimated as $19.8 \%$, with larger uncertainty occurring in regions with lower grassland biomass. The determination of BMallo was the primary uncertainty source of regional grassland biomass estimation (52\%), followed by types of remote sensing DATsrc (27\%) and MODfrm (13\%). This study suggested a need to concern the uncertainty in grassland biomass estimation, especially for the uncertainty related to BMallo. Our analysis provides an alternative and quantitative fashion that can be used in regional carbon storage evaluation.

\section{Acknowledgments}

This study benefited from the NASA's Earth Observing System (EOS) Data Gateway for the AVHRR, SPOT-VGT, and MODIS NDVI products. This study was supported by the Non-profit Special Research fund of National Environmental Protection of China (201109030), the Science and Technology Projects of China on "Certified carbon budget affected by climate change and related issues" (grant XDA05050700), and the National Natural Science Foundation of China (grant 41201092, 41471076). The authors thank Dr.
Varenyam Achal for revising and polishing the English writing. We are also very grateful for three anonymous reviewers in providing invaluable suggestions and comments, which helped us to improve this manuscript.

\section{Appendix A. Supplementary data}

Supplementary data associated with this article can be found, in the online version, at http://dx.doi.org/10.1016/j.ecolind.2015. 09.001.

\section{References}

Anaya, J.A., Chuvieco, E., Palacios-Orueta, A., 2009. Aboveground biomass assessment in Colombia: a remote sensing approach. Forest Ecol. Manag. 257 (4), 1237-1246, http://dx.doi.org/10.1016/j.foreco.2008.11.016.

Blanco, C.C., Scheiter, S., Sosinski, E., Fidelis, A., Anand, M., Pillar, V.D., 2014. Feedbacks between vegetation and disturbance processes promote long-term persistence of forest-grassland mosaics in south Brazil. Ecol. Model. 291, 224-232, http://dx.doi.org/10.1016/j.ecolmodel.2014.07.024.

Burnham, K.P., Anderson, D.R., 2002. Model Selection and Multimodel Inference: A Practical Information-theoretic Approach, 2nd ed. Springer-Verlag, ISBN:0-38795364-7.

Carilla, J., Aragón, R., Gurvich, D.E., 2011. Fire and grazing differentially affect aerial biomass and species composition in Andean grasslands. Acta Oecol. 37 (4), 337-345, http://dx.doi.org/10.1016/j.actao.2011.03.006.

Chen, B.X., Zhang, X.Z., Tao, J., Wu, J.S., Wang, J.S., Shi, P.L., Zhang, Y.J., Yu, C.Q., 2014. The impact of climate change and anthropogenic activities on alpine grassland over the Qinghai-Tibet Plateau. Agr. Forest Meteorol. 189-190, 11-18, http://dx. doi.org/10.1016/j.agrformet.2014.01.002.

Chinese Academy of Sciences, 2001. Vegetation Atlas of China. Science Press, Beijing.

Enquist, B.J., Niklas, K.J., 2002. Global allocation rules for patterns of biomass partitioning in seed plants. Science 295, 1517-1520.

Fan, J.W., Zhong, H.P., Harris, W., Yu, G.R., Wang, S.Q., Hu, Z.M., Yue, Y.Z., 2007. Carbon storage in the grasslands of China based on field measurements of above- and below-ground biomass. Clim. Change 86, 375-396, http://dx.doi.org/10.1007/ s10584-007-9316-6.

Fang, J.Y., Yang, Y.H., Ma, W.H., Mohammat, A., Shen, H.H., 2010. Ecosystem carbon stocks and their changes in China's grasslands. Sci. China Life Sci. 53 (7), 757-765, http://dx.doi.org/10.1007/s11427-010-4029-x.

Fensholt, R., Proud, S.R., 2012. Evaluation of earth observation based global long term vegetation trends - comparing GIMMS and MODIS global NDVI time series. Remote Sens. Environ. 119, 131-147, http://dx.doi.org/10.1016/j.rse.2011.12. 015.

Gaitan, J.J., Bran, D., Oliva, G., Ciari, G., Nakamatsu, V., Salomone, J., Ferrante, D., Buono, G., Massara, V., Humano, G., Celdran, D., Opazo, W., Maestre, F.T., 2013. Evaluating the performance of multiple remote sensing indices to predict the 
spatial variability of ecosystem structure and functioning in Patagonian steppes. Ecol. Indic. 34, 181-191, http://dx.doi.org/10.1016/j.ecolind.2013.05.007.

Gao, T., Yang, X.C., Jin, Y.X., Ma, H.H., Li, J.Y., Yu, H.D., Yu, Q.Y., Zheng, X., Xu, B., 2013a. Spatio-temporal variation in vegetation biomass and its relationships with climate factors in the Xilingol grasslands, Northern China. PLOS ONE 8 (12), e83824, http://dx.doi.org/10.1371/journal.pone.0083824.

Gao, T., Xu, B., Yang, X.C., Jin, Y.X., Ma, H.H., Li, J.Y., Yu, H.D., 2013b. Using MODIS time series data to estimate aboveground biomass and its spatio-temporal variation in Inner Mongolia's grassland between 2001 and 2011. Int. J. Remote Sens. 34 (21), 7796-7810, http://dx.doi.org/10.1080/01431161.2013.823000.

He, H.L., Liu, M., Xiao, X.M., Ren, X.L., Zhang, L., Sun, X.M., Yang, Y.H., Li, Y.N., Zhao, L. Shi, P.L., Du, M.Y., Ma, Y.M., Ma, M.G., Zhang, Y., Yu, G.R., 2014. Large-scale estimation and uncertainty analysis of gross primary production in Tibetan alpine grasslands. J. Geophys. Res. Biogeogr. 119 (3), 466-486, http://dx.doi.org/10. 1002/2013jg002449.

Holben, B.N., 1986. Characteristics of maximum-value composite images from temporal AVHRR data. Int. J. Remote Sens. 7 (11), 1417-1434.

Hsu, J.S., Powell, J., Adler, P.B., 2012. Sensitivity of mean annual primary production to precipitation. Global Change Biol. 18 (7), 2246-2255.

Jiang, Y.B., Tao, J., Huang, Y.Q., Zhu, J.T., Tian, L., Zhang, Y.J., 2014. The spatial pattern of grassland aboveground biomass on Xizang Plateau and its climatic controls. J. Plant Ecol., http://dx.doi.org/10.1093/jpe/rtu002.

Jin, Y.X., Yang, X.C., Qiu, J.J., Li, J.Y., Gao, T., Wu, Q., Zhao, F., Ma, H.L., Yu, H.D., Xu, B., 2014. Remote sensing-based biomass estimation and its spatio-temporal variations in temperate grassland, Northern China. Remote Sens. 6 (2), 1496-1513, http://dx.doi.org/10.3390/rs6021496.

Kang, M., Dai, C., Ji, W.Y., Jiang, Y., Yuan, Z.Y., Chen, H.Y.H., 2013. Biomass and its allocation in relation to temperature, precipitation, and soil nutrients in Inner Mongolia grasslands, China. PLOS ONE 8 (7), e69561, http://dx.doi.org/10.1371/ journal.pone.0069561.

Kawamura, K., Akiyama, T., Yokota, H., Tsutsumi, M., Yasuda, T., Watanabe, O., Wang, G., Wang, S., 2005. Monitoring of forage conditions with MODIS imagery in the Xilingol steppe, Inner Mongolia. Int. J. Remote Sens. 26 (7), 1423-1436, http:// dx.doi.org/10.1080/01431160512331326783.

Keenan, T.F., Carbone, M.S., Reichstein, M., Richardson, A.D., 2011. The model-data fusion pitfall: assuming certainty in an uncertain world. Oecologia 167 (3), 587-597, http://dx.doi.org/10.1007/s00442-011-2106-x.

Kottek, M., Grieser, J., Beck, C., Rudolf, B., Rubel, F., 2006. World map of the Köppen-Geiger climate classification updated. Meteorol. Z. 15 (3), 259-263.

Lauenroth, W.K., Wade, A.A., Williamson, M.A., Ross, B.E., Kumar, S., Cariveau, D.P., 2006. Uncertainty in calculations of net primary production for grasslands. Ecosystems 9 (5), 843-851, http://dx.doi.org/10.1007/s10021-005-0072-z.

Luo, T.X., Li, W.H., Zhu, H.Z., 2002. Estimated biomass and productivity of natural vegetation on the Tibetan Plateau. Ecol. Appl. 12 (4), 980-997, http://dx.doi.org/ $10.2307 / 3061031$.

Ma, W.H., Fang, J.Y., Yang, Y.H., Mohammat, A., 2010. Biomass carbon stocks and their changes in Northern China's grasslands during 1982-2006. Sci. China Life Sci. 53 (7), 841-850, http://dx.doi.org/10.1007/s11427-010-4020-6.

Mao, D.H., Wang Z.M. Li. L. Ma, W.H., 2014 Spatiotemporal dynamics of grassland aboveground net primary productivity and its association with climatic pattern and changes in Northern China. Ecol. Indic. 41, 40-48, http://dx.doi.org/10.1016/ j.ecolind.2014.01.020.

Mokany, K., Raison, R.J., Prokushkin, A.S., 2006. Critical analysis of root: shoot ratios in terrestrial biomes. Global Change Biol. 12 (1), 84-96, http://dx.doi.org/10. $1111 / \mathrm{j} .1365-2486.2005 .001043 . x$.

Muukkonen, P., Heiskanen, J., 2007. Biomass estimation over a large area based on standwise forest inventory data and ASTER and MODIS satellite data: a possibility to verify carbon inventories. Remote Sens. Environ. 107 (4), 617-624, http:// dx.doi.org/10.1016/j.rse.2006.10.011

$\mathrm{Ni}$, J., 2002. Carbon storage in grasslands of China. J. Arid Environ. 50 (2), 205-218, http://dx.doi.org/10.1006/jare.2001.0902.

$\mathrm{Ni}$, J., 2004. Forage yield-based carbon storage in grasslands of China. Clim. Change $67,237-246$

Niklas, K.J., 2005. Modelling below- and above-ground biomass for non-woody and woody plants. Ann. Bot. 95 (2), 315-321, http://dx.doi.org/10.1093/aob/mci028.

Ogle, S.M., Breidt, F.J., Easter, M., Williams, S., Killian, K., Paustian, K., 2010. Scale and uncertainty in modeled soil organic carbon stock changes for US croplands using a process-based model. Global Change Biol. 16 (2), 810-822, http://dx.doi. org/10.1111/j.1365-2486.2009.01951.x.

Oliveras, I., van der Eynden, M., Malhi, Y., Cahuana, N., Menor, C., Zamora, F., Haugaasen, T., 2014. Grass allometry and estimation of above-ground biomass in tropical alpine tussock grasslands. Austral. Ecol. 39 (4), 408-415, http://dx.doi. org/10.1111/aec.12098.
Piao, S.L., Fang,J.Y.,Zhou, L.M., Tan, K., Tao, S., 2007. Changes in biomass carbon stocks in China's grasslands between 1982 and 1999. Global Biogeochem. Cycles 21 (2), http://dx.doi.org/10.1029/2005gb002634.

Plischke, E., Borgonovo, E., Smith, C.L., 2013. Global sensitivity measures from given data. Eur. J. Oper. Res. 226 (3), 536-550, http://dx.doi.org/10.1016/j.ejor.2012. 11.047.

Rahman, A.F., Gamon, J.A., Sims, D.A., Schmidts, M., 2003. Optimum pixel size for hyperspectral studies of ecosystem function in southern California chaparral and grassland. Remote Sens. Environ. 84 (2), 192-207, http://dx.doi.org/10.1016/ S0034-4257(02)00107-4.

Ruppert, J.C., Linstädter, A., 2014. Convergence between ANPP estimation methods in grasslands - a practical solution to the comparability dilemma. Ecol. Indic. 36, 524-531, http://dx.doi.org/10.1016/j.ecolind.2013.09.008.

Ruppert, J.C., Harmoney, K., Henkin, Z., Snyman, H.A., Sternberg, M., Willms, W. Linstadter, A., 2015. Quantifying drylands' drought resistance and recovery: the importance of drought intensity, dominant life history and grazing regime. Global Change Biol. 21 (3), 1258-1270, http://dx.doi.org/10.1111/gcb.12777.

Scurlock, J.M.O., Hall, D.O., 1998. The global carbon sink: a grassland perspective. Global Change Biol. 4(2), 229-233, http://dx.doi.org/10.1046/j.1365-2486.1998. 00151.x.

Scurlock, J.M.O., Johnson, K., Olson, R.J., 2002. Estimating net primary productivity from grassland biomass dynamics measurements. Global Change Biol. 8 (8) 736-753, http://dx.doi.org/10.1046/j.1365-2486.2002.00512.x.

Tarnavsky, E., Garrigues, S., Brown, M.E., 2008. Multiscale geostatistical analysis of AVHRR, SPOT-VGT, and MODIS global NDVI products. Remote Sens. Environ. 112 (2), 535-549, http://dx.doi.org/10.1016/j.rse.2007.05.008.

Taylor, K.E., 2001. Summarizing multiple aspects of model performance in a single diagram. J. Geophys. Res. 106 (D7), 7183-7192, http://dx.doi.org/10.1029/ 2000jd900719.

Tucker, C.J., Vanpraet, C.L., Sharman, M.J., Van Ittersum, G., 1985. Satellite remote sensing of total herbaceous biomass production in the senegalese sahel 1980-1984. Remote Sens. Environ. 17 (3), 233-249, http://dx.doi.org/10.1016/ 0034-4257(85)90097-5.

Tucker, C.J., Pinzon, J.E., Brown, M.E., 2004. Global Inventory Modeling and Mapping Studies (GIMMS) Satellite Drift Corrected and NOAA-16 Incorporated Normalized Difference Vegetation Index (NDVI), Monthly 1981-2002. University of Maryland, College Park.

Tucker, C., Pinzon, J., Brown, M., Slayback, D., Pak, E., Mahoney, R., Vermote, E., El Saleous, N. 2005. An extended AVHRR 8-km NDVI dataset compatible with MODIS and SPOT vegetation NDVI data. Int. J. Remote Sens. 26 (20), 4485-4498, http:// dx.doi.org/10.1080/01431160500168686.

Valone, T.J., Kelt, D.A., 1999. Fire and grazing in a shrub-invaded arid grassland community: independent or interactive ecological effects? J. Arid Environ. 42 (1) 15-28, http://dx.doi.org/10.1006/jare.1999.0500.

Verstraeten, W.W., Veroustraete, F., Heyns, W., Van Roey, T., Feyen, J., 2008. On uncertainties in carbon flux modelling and remotely sensed data assimilation: the Brasschaat pixel case. Adv. Space Res. 41 (1), 20-35.

Vogt, K.A., Persson, H., 1991. Measuring growth and development of roots. In Lassoie, J.L., Hinckley, T.M. (Eds.), Techniques and Approaches in Forest Tree Ecophysiology. CRC, Boca Raton, pp. 477-502.

Wang, C.Z., Guo, H.D., Zhang, L., Liu, S.Y., Qiu, Y.B., Sun, Z.C., 2014. Assessing phenological change and climatic control of alpine grasslands in the Tibetan Plateau with MODIS time series. Int. J. Biometeorol., http://dx.doi.org/10.1007/s00484014-0817-5.

Wang, L., Niu, K.C., Yang, Y.H., Zhou, P., 2010. Patterns of above- and belowground biomass allocation in China's grasslands: evidence from individual-level observations. Sci. China Life Sci. 53 (7), 851-857, http://dx.doi.org/10.1007/s11427010-4027-z.

World Resources Institute, 2000. Downloaded from: http://earthtrends.wri.org/ text/forests-grasslands-drylands/map-229.htm.

Xia, J.Z., Liu, S.G., Liang, S.L., Chen, Y., Xu, W.F., Yuan, W.P., 2014. Spatio-temporal patterns and climate variables controlling of biomass carbon stock of global grassland ecosystems from 1982 to 2006. Remote Sens. 6 (3), 1783-1802, http:/ dx.doi.org/10.3390/rs6031783.

Xu, B., Yang, X.C., Tao, W.G., Qin, Z.H., Liu, H.Q., Miao, J.M., Bi, Y.Y., 2008. MODIS-based remote sensing monitoring of grass production in China. Int. J. Remote Sens. 29 (17-18), 5313-5327, http://dx.doi.org/10.1080/01431160802036276.

Yang, Y.H., Fang, J.Y., Pan, Y.D., Ji, C.J., 2009. Aboveground biomass in Tibetan grasslands. J. Arid Environ. 73 (1), 91-95, http://dx.doi.org/10.1016/j.jaridenv.2008. 09.027.

Yang, Y.H., Fang, J.Y., Ma, W.H., Guo, D.L., Mohammat, A., 2010. Large-scale pattern of biomass partitioning across China's grasslands. Global Ecol. Biogeogr. 19 (2), 268-277, http://dx.doi.org/10.1111/j.1466-8238.2009.00502.x. 